\title{
Anatomical Changes at the Level of the Primary Synapse in Neuropathic Pain: Evidence from the Spinal Trigeminal Nucleus
}

\author{
Sophie L. Wilcox, ${ }^{1}$ Sylvia M. Gustin, ${ }^{1}$ Paul M. Macey, ${ }^{2}$ Chris C. Peck, ${ }^{3}$ Greg M. Murray, ${ }^{3}$ and $\odot$ Luke A. Henderson ${ }^{1}$ \\ ${ }^{1}$ Department of Anatomy and Histology, University of Sydney, Sydney, New South Wales, Australia 2006, ${ }^{2}$ University of California, Los Angeles, School of \\ Nursing and Brain Research Institute, Los Angeles, California 90095, and ${ }^{3}$ Jaw Function and Orofacial Pain Research Unit, Faculty of Dentistry, Westmead \\ Hospital, University of Sydney, Australia 2145
}

Accumulated evidence from experimental animal models suggests that neuronal loss within the dorsal horn is involved in the development and/or maintenance of peripheral neuropathic pain. However, to date, no study has specifically investigated whether such neuroanatomical changes also occur at this level in humans. Using brain imaging techniques, we sought to determine whether anatomical changes were present in the spinal trigeminal nucleus in subjects with chronic orofacial neuropathic pain. In 22 subjects with painful trigeminal neuropathy and 44 pain-free controls, voxel-based morphometry of T1-weighted anatomical images and diffusion tensor images were used to assess regional gray matter volume and microstructural changes within the brainstem. In addition, deterministic tractography was used to assess the integrity of ascending pain pathways. Orofacial neuropathic pain was associated with significant regional gray matter volume decreases, fractional anisotropy increases, and mean diffusivity decreases within the spinal trigeminal nucleus, specifically the subnucleus oralis. In addition, tractography revealed no significant differences in diffusivity properties in the root entry zone of the trigeminal nerve, the spinal trigeminal tract, or the ventral trigeminothalamic tracts in painful trigeminal neuropathy subjects compared with controls. These data reveal that chronic neuropathic pain in humans is associated with discrete alterations in the anatomy of the primary synapse. These neuroanatomical changes may be critical for the generation and/or maintenance of pathological pain.

Key words: brainstem; dorsal horn; magnetic resonance imaging; tractography; trigeminal neuropathy

\section{Introduction}

Half a century ago, Melzack and Loeser (1978) suggested that the maintenance of some chronic neuropathic conditions may result from neural processes well above the level of the initiating injury. More recently, structural imaging has shown that chronic neuropathic pain is associated with anatomical changes of higher brain structures, including those in the classical sensory-discriminative pain pathway such as the thalamus and somatosensory cortices (May, 2008; Tracey and Bushnell, 2009; Gustin et al., 2011). However, Melzack and Loeser (1978) and others also acknowledged the undoubted role of peripheral/primary factors in the initiation of these higher changes (Katz and Seltzer, 2009). Indeed, animal models of neuropathic pain show neuroplastic changes at the primary synapse; the spinal dorsal horn, or spinal

\footnotetext{
Received Sept. 9, 2014; revised Dec. 22, 2014; accepted Dec. 29, 2014.

Author contributions:S.M.G., C.C.P., G.M.M., and L.A.H. designed research;S.L.W., S.M.G., and L.A.H. performed research; S.L.W. and P.M.M. analyzed data; S.L.W., S.M.G., P.M.M., C.C.P., G.M.M., and L.A.H. wrote the paper.

This work was supported by the National Health and Medical Research Council of Australia and the Australian Dental Foundation.

The authors declare no competing financial interests.

Correspondence should be addressed to Luke Henderson, Department of Anatomy and Histology, University of Sydney, Sydney, Australia 2006. E-mail: lukeh@anatomy.usyd.edu.au.

DOI:10.1523/JNEUROSCI.3756-14.2015

Copyright $\odot 2015$ the authors $\quad 0270-6474 / 15 / 352508-08 \$ 15.00 / 0$
}

trigeminal nucleus (SpV) (Woolf, 1993; Costigan et al., 2009). Similar to the volumetric changes in higher brain regions of humans with pain, these animal models demonstrate neuronal degeneration/apoptosis in the superficial spinal dorsal horn or SpV (Sugimoto et al., 1990; Whiteside and Munglani, 2001; Scholz et al., 2005). These animal models raise the possibility that human neuropathic pain is also characterized by anatomical changes at the level of the primary synapse that may contribute to the maintenance and/or modulation of ongoing neuropathic pain.

To date, no study has focused on the anatomy at the level of the primary synapse in humans with chronic pain. This lack of focus is likely related to technical difficulties in exploring the anatomy in this extremely small region, particularly in the case of the spinal dorsal horn, in humans with magnetic resonance imaging (MRI) (Valsasina et al., 2012). However, in the orofacial system, the $\mathrm{SpV}$, including the medullary dorsal horn (SpV caudalis), lies within the caudal brainstem. Given the available spatial resolution of anatomical MRI, it is now possible to explore the anatomy of this brainstem region in humans (Lambert et al., 2013), including those with chronic orofacial pain conditions.

The aim of this investigation was to use anatomical MRI techniques to explore brainstem anatomy, particularly the $\mathrm{SpV}$, in individuals with painful trigeminal neuropathy (PTN), a chronic neuropathic pain condition that likely results from direct trauma 
Table 1. PTN subject (subgroup posttraumatic neuropathy) characteristics

\begin{tabular}{lllllll}
\hline Subject & Age $(\mathrm{y})$ & Sex & Pain duration (y) & Site & Pain rating (0-10 NRS) & Analgesic medication \\
\hline 1 & 51 & M & 3.5 & Right & 5.5 & Amitriptyline hydrochloride \\
2 & 48 & $\mathrm{~F}$ & 9 & Bilateral & 4 & Gabapentin \\
3 & 42 & $\mathrm{~F}$ & 2 & Right & 4.5 & Neurontin \\
4 & 64 & $\mathrm{~F}$ & 11 & Right & 5 & Gabapentin \\
5 & 52 & $\mathrm{~F}$ & 3.5 & Right & 4.5 & None \\
6 & 47 & $\mathrm{~F}$ & 5 & Left & 1.5 & None \\
7 & 53 & $\mathrm{~F}$ & 2.5 & Right & 4 & Gabapentin, oxycodone, paracetamol \\
8 & 52 & $\mathrm{~F}$ & 1.5 & Bilateral & 8 & None \\
9 & 45 & $\mathrm{M}$ & 9 & Bilateral & 4 & Diazepam, paracetamol, ibuprofin (PRN) \\
10 & 46 & $\mathrm{~F}$ & 3 & Left & 6 & Carbamazepine, paracetamol \\
11 & 42 & $\mathrm{~F}$ & 11 & Bilateral & 7 & Gabapentin \\
12 & 48 & $\mathrm{~F}$ & 1.3 & Bilateral & 6 & Pregabalin, Nortriptyline \\
13 & 33 & $\mathrm{M}$ & 5 & Bilateral & 3 & Doxylamine, paracetamol \\
14 & 59 & $\mathrm{~F}$ & 5 & Left & 3.5 & Amitriptyline \\
15 & 54 & $\mathrm{~F}$ & 2 & Right & 3 & None \\
16 & 44 & $\mathrm{~F}$ & 3.5 & Bilateral & 7 & Carbamazepine \\
17 & 41 & $\mathrm{~F}$ & 6.5 & Bilateral & 7 & Desvenlafaxine \\
18 & 43 & $\mathrm{M}$ & 16 & Left & 6 & Paracetamol, ibuprofen (PRN) \\
19 & 44 & $\mathrm{~F}$ & 2 & Bilateral & 3.5 & None \\
20 & 65 & $\mathrm{~F}$ & 7 & Bilateral & 5 & None \\
21 & 50 & $\mathrm{~F}$ & 7 & Right & 1 & \\
Mean & 48.7 & & & 4.7 & \\
\hline
\end{tabular}

NRS, Numeric rating scale; PRN, pro re nata (as needed).

to the trigeminal nerve (Iwata et al., 2011). We have previously reported that this condition is associated with regional anatomical changes in higher brain areas of the pain pathway, including the thalamus, primary somatosensory cortex, and insula (Gustin et al., 2011). Based on this evidence of central anatomical changes at higher subcortical and cortical levels (i.e., thalamus and cortex), we hypothesize that anatomical changes are also present in the preceding level of the ascending pathway, particularly at the level of the primary synapse $(\mathrm{SpV})$. Voxel-based morphometry (VBM) of T1-weighted anatomical and diffusion weighted images was used to determine changes in regional brainstem anatomy and deterministic tractography to assess the integrity of ascending pathways. We hypothesized that PTN will be associated with decreased volume and diffusion changes in the SpV caudalis and altered integrity of the ascending pain pathway as a result of neuroplastic changes at the level of the primary synapse.

\section{Materials and Methods}

\section{Subjects}

Twenty-one subjects with PTN [4 males, mean age ( \pm SEM): $48.7 \pm 1.7$ ] and 42 age- and sex-matched pain-free controls ( 8 males, age: $48.6 \pm 2.0)$ were recruited. There was no significant difference in age ( $t$ test; $p>0.05)$ or sex composition $\left(\chi^{2}\right.$ test, $\left.p>0.05\right)$ between the two groups. All subjects were recruited from the Faculty of Dentistry, Westmead Hospital, University of Sydney, during a period from August 2006 to November 2012. Individual PTN subject demographics are given in Table 1. PTN subjects were diagnosed according to the Liverpool criteria (Nurmikko and Eldridge, 2001) by a clinician (C.C.P.) in the research group. Controls were screened by self-report for chronic pain (pain lasting for $>3$ months), current usage of analgesic medication, or any neurological disorder. Informed written consent was obtained for all procedures according to the Declaration of Helsinki and the study was approved by local institutional human research ethics committees. Some of the subjects used in this study were also used in previous investigations (Gustin et al., 2011; Gustin et al., 2012; Henderson et al., 2013; Wilcox et al., 2013).

\section{Pain measures}

Each PTN subject's pain was assessed according to: (1) intensity as a numeric rating on a scale from 0 (no pain) to 10 (worst pain imaginable); (2) location as a distribution map of their ongoing pain onto a standard drawing of the face; and (3) quality by the McGill Pain Questionnaire (Melzack, 1975).

\section{MRI scans}

All subjects lay supine on the bed of a 3 tesla MRI scanner (Intera; Philips) with their head immobilized in a tight-fitting head coil. In each subject, 3 high-resolution 3D T1-weighted anatomical image sets covering the entire brain were collected (turbo field echo; echo time $=2.5 \mathrm{~ms}$, repetition time $5600 \mathrm{~ms}$, flip angle $=8^{\circ}$, voxel size $0.8 \times 0.8 \times 0.8 \mathrm{~mm}$ ). The three acquisitions were acquired to allow averaging for improved signal-to-noise ratios. In 16 of 21 PTN and 21 of 42 controls subjects (PTN: 3 males, mean age $48.8 \pm 1.6$ years; controls: 2 males, mean age $50.1 \pm 3.3$, no significant difference in age or sex), four high-resolution diffusion tensor imaging (DTI) image sets covering the entire brain were collected using a single-shot multisection spin-echo echo-planar pulse sequence (repetition time $=8788 \mathrm{~ms}$; flip angle $=90^{\circ}$, matrix size $=$ $112 \times 112$, field of view $=224 \times 224 \mathrm{~mm}$, slice thickness $=2.5 \mathrm{~mm}, 55$ axial slices). For each slice, diffusion gradients were applied along 32 independent orientations with $b=1000 \mathrm{~s} / \mathrm{mm}^{2}$ after the acquisition of $b=0 \mathrm{~s} / \mathrm{mm}^{2}\left(b_{0}\right)$ images. Four acquisitions were acquired to improve signal-to-noise ratios in measurements derived from the DTI data.

\section{MRI analysis}

Brainstem VBM. Using SPM8 (Friston et al., 1994), the three T1weighted images from each subject were coregistered and averaged. The mean images were segmented and spatially normalized with a dedicated symmetrical brainstem template. In brief, using the SUIT toolbox (Diedrichsen, 2006), each image was cropped and the brainstem masked before spatial normalization. The subsequent spatial normalization and reslicing produced brainstem "maps" of gray matter probabilities modulated by the volume changes due to the normalization. Finally, the images were resliced into Montreal Neurological Institute (MNI) space and spatially smoothed using a Gaussian filter $(3 \mathrm{~mm}$ full-width-halfmaximum). In addition, given that subjects had unilateral or asymmetrical pain, their images were reflected in the $X$ plane ("flipped") so that changes in gray matter could be assessed ipsilateral and contralateral to the (highest) side of ongoing pain. Significant differences in gray matter between PTN and control subjects were determined using a voxel-byvoxel analysis (uncorrected, $p<0.001$ ). Clusters of significant difference were then overlaid onto the T1-weighted template image for visualization. The location of these clusters in relation to SpV subnuclei in par- 

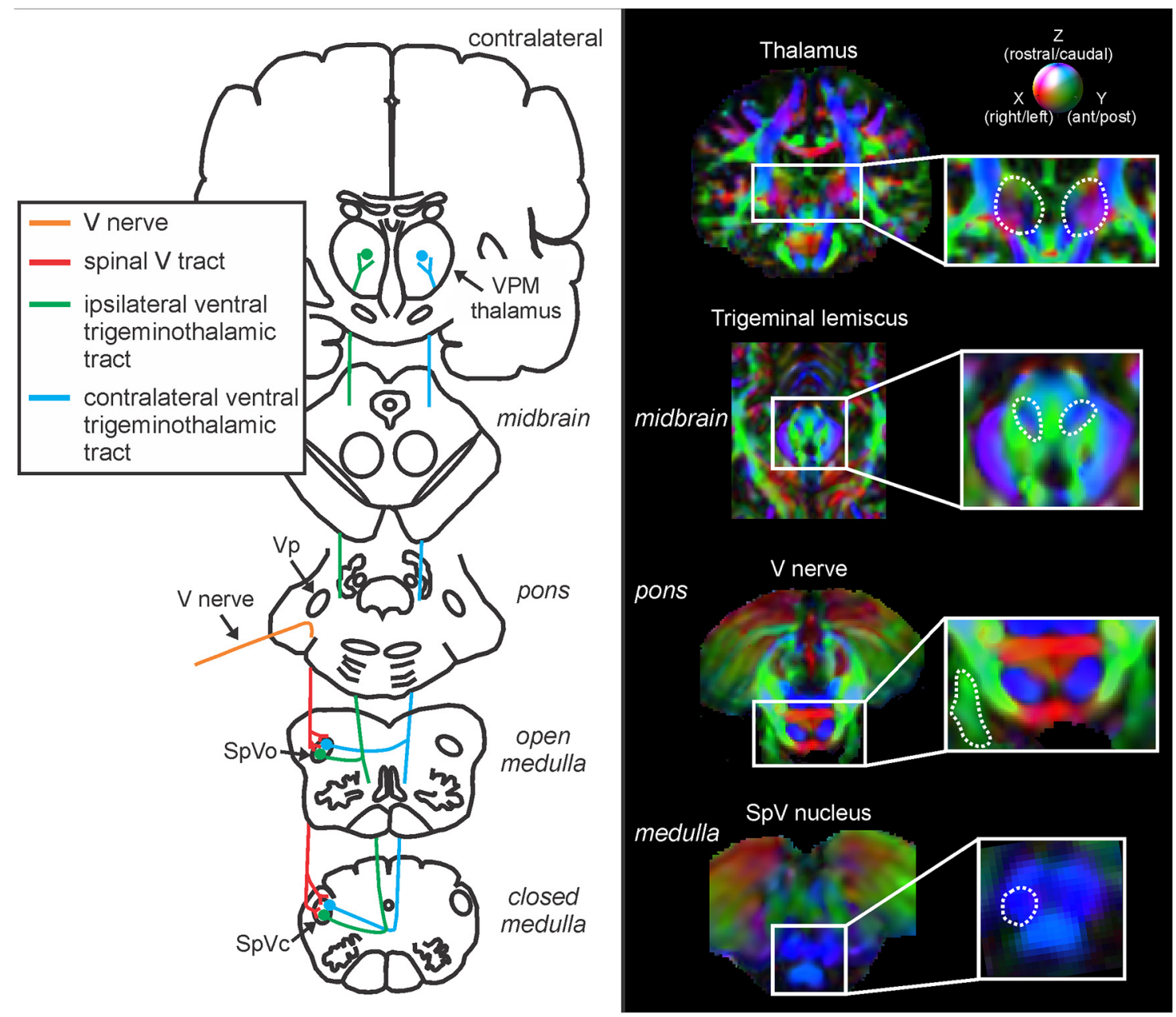

Figure 1. Left, Diagram of the pathway of the trigeminal nerve, the spinal trigeminal tract, and the ipsilateral and contralateral trigeminothalamic tracts. Right, Volumes of interest (VOIs) used to define the tracts of interest: the trigeminal root entry zone, the spinal trigeminal nucleus caudalis (SpVc), trigeminal lemniscus, and thalamus. The dashed lines indicate the boundaries of each V0I overlaid on a vector RGB map (color-coded for direction: green, anterior-posterior; red, medial-lateral; and blue, inferior-superior) of an individual's brain.

ticular were identified using Duvernoy's Atlas of the Human Brainstem and Cerebellum (Naidich et al., 2009) and the Atlas of the Human Brainstem by Paxinos and Huang (1995). Individual gray matter volumes (probability ${ }^{\star}$ volume) were also extracted from clusters of significant difference and correlations between these gray matter volumes and pain characteristics - that is, intensity and duration-were assessed (Pearson $r$, $p<0.05$ ). In addition, to test for a possible confound of medication usage, the gray matter volumes were compared (2-sample $t$ test) between PTN subjects using prescribed analgesic medication $(n=13)$ and those who were not or only using NSAIDs occasionally $(n=8)$.

Brainstem DTI. Using SPM8 and custom software, the four DTI sets were realigned based on the b0 images in each series. The diffusion tensor was calculated from the images using a linear model, and fractional anisotropy (FA) and mean diffusivity (MD) whole-brain maps were derived. These images were spatially normalized and resliced using the SUIT template as mentioned previously. This process resulted in brainstem maps of diffusion values, spatially normalized in MNI space with raw intensities preserved (nonmodulated). The images were then smoothed (3 mm full-width-half-maximum) and reflected across the midline as described above. Significant differences in diffusion values between PTN subjects and controls were determined using a voxel-byvoxel analysis (false discovery rate corrected for multiple comparisons, $p<0.005)$. Significant DTI differences were then overlaid onto the template T1-weighted image for visualization. Subsequently, individual diffusion values were extracted from clusters of significant difference, and correlations between MD and FA and pain characteristics - that is, pain intensity and duration-were assessed (Pearson $r, p<0.05$ ). In addition, to test for a possible confound of medication usage, the MD values were compared (2-sample $t$ test) between PTN subjects using analgesic medication $(n=12)$ and those who were not $(n=4)$.

Deterministic tractography. Tractography was performed using MrDiffusion software (Dougherty et al., 2005) based on the diffusion tensor calculated as described above. Four fiber pathways were targeted: the root entry zone (REZ) of the trigeminal nerve, the spinal trigeminal tract, and the ipsilateral and contralateral ventral trigeminothalamic tracts. Four volumes of interest were specified anatomically in each individual subject in native space: the REZ of the trigeminal nerve, the caudal SpV nucleus, the medial lemiscus in the midbrain, and the thalamus (Fig. 1). Fibers were tracked using a Runge-Kutta fourth-order algorithm with a minimum FA value of 0.15 and a maximum turning angle of $60^{\circ}$. The REZ of the trigeminal nerve was defined as encompassing the trigeminal nerve within the pontine cistern; that is, from the point at which the nerve emerges from the pons to the point at which it exits the pontine cistern anteriorly. Fibers of the trigeminal nerve that descended to $\mathrm{SpV}$ caudalis were classified as the spinal trigeminal tract. The ipsilateral ventral trigeminothalamic tract was defined as fibers that originated in the SpV caudalis and passed through the ipsilateral medial lemiscus to the thalamus. The contralateral trigeminothalamic tract was defined as fibers that originated in the $\mathrm{SpV}$ caudalis and passed through the contralateral medial lemiscus to the thalamus. The mean FA and MD diffusivity values for each of the tracts were calculated in each individual. For controls, left and right tract FA and MD values were compared using paired $t$ tests. These were not significantly different (all $p>0.05$ ) and were subsequently combined for comparison with PTN subjects. Finally, significant differ- 


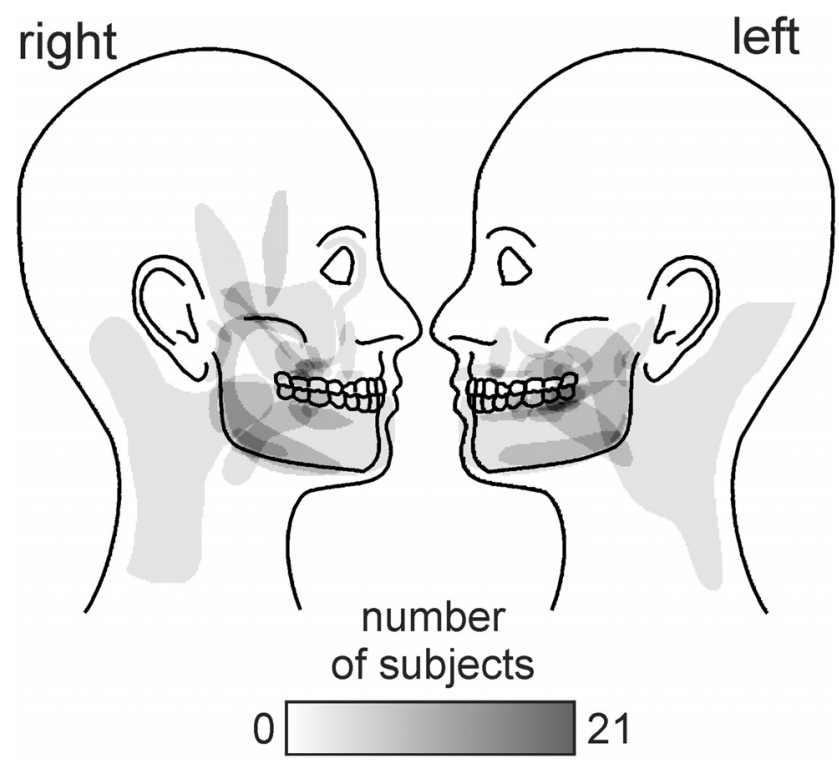

Figure 2. Density of pain distribution of subjects with PTN. Regions are color-coded according to the number of subjects with pain in that location (see white-gray-black scale bar).

ences between control and PTN tract FA and MD values were determined (two-sample $t$ test, $p<0.05$ ).

\section{Results}

\section{Pain characteristics}

Individual PTN subject characteristics are shown in Table 1. All of the 21 PTN subjects were classified as having posttraumatic neuropathy. In 10 of the PTN subjects, ongoing pain was unilateral (60\% right, 40\% left side) and the remaining subjects had bilateral pain. A cumulative distribution map of their pain distribution is shown in Figure 2. In most PTN subjects, pain was located in the maxillary and/or mandibular nerve distributions, with most subjects reporting pain in the oral/perioral region. Their average pain intensity (numeric rating scale) was $4.7 \pm 0.4$ and their average duration of pain was $5.5 \pm 0.8$ years. PTN subjects most commonly described their pain as radiating $(42 \%)$, shooting (29\%), and sharp (29\%).

\section{Gray matter volume changes (VBM)}

In PTN subjects, brainstem VBM analysis revealed significant regional gray matter volume changes in several regions (Fig. 3, Table 2). Compared with control subjects, PTN subjects displayed significant reductions in gray matter volume in the ipsilateral (to higher pain) $\mathrm{SpV}$. This $\mathrm{SpV}$ volume decrease was in the region of the subnucleus oralis (mean \pm SEM gray matter probability $^{\star}$ volume: controls $0.17 \pm 0.006$, PTN $0.14 \pm 0.006$ ). Significant reductions in gray matter volume in PTN subjects also occurred in the region of the ipsilateral principal trigeminal sensory nucleus $(\mathrm{Vp})$ (controls $0.21 \pm 0.008$, PTN $0.16 \pm 0.010)$, in the contralateral middle cerebellar peduncle (MCP) (controls $0.15 \pm 0.007$, PTN $0.10 \pm 0.006$ ), and in the ipsilateral trigeminal lemniscus (TL) in the midbrain (controls $0.17 \pm 0.006$, PTN $0.12 \pm 0.008)$. No brainstem region showed increased gray matter volume in PTN subjects compared with controls.

In PTN subjects, no significant correlations were observed between gray matter volume in any cluster of significant difference and pain intensity (SpV: $r=0.02$; Vp: $r=0.30$; MCP: $r=$ 0.36 ; TL: $r=-0.03$; all $p>0.05)$ or pain duration (SpV: $r=0.30$; Vp: $r=-0.06$; MCP: $r=0.29$; TL: $r=0.02$; all $p>0.05$ ).
Furthermore, comparison of these clusters found no significant difference in MD values between those PTN subjects who used analgesic medication and those who did not.

\section{DTI changes}

In addition to changes in gray matter volume, DTI analysis revealed significant MD differences in a number of brainstem sites (Fig. 3, Table 2). Compared with controls, PTN subjects had significantly decreased MD in the region of the ipsilateral SpV; specifically, in separate clusters in the region of the subnucleus interpolaris (mean $\pm \mathrm{SEM} \times 10^{-3} \mathrm{MD}$ : controls $0.91 \pm 0.03$, PTN $0.79 \pm 0.01$ ) and subnucleus oralis (controls $0.92 \pm 0.02$, PTN $0.79 \pm 0.01$ ), in the region of the trigeminal nerve entry within the pons (ipsilateral: controls $0.81 \pm 0.01$, PTN $0.71 \pm 0.01$ ), bilateraly in the region of $\mathrm{Vp}$ (ipsilateral: controls $0.87 \pm 0.02$, PTN $0.75 \pm 0.02$; contralateral: controls $0.90 \pm 0.02$, PTN $0.78 \pm 0.01$ ), and in the ipsilateral TL in the midbrain (controls $0.87 \pm 0.01$, PTN $0.73 \pm 0.01)$. No increases in MD were observed.

In these significant clusters, in PTN subjects, significant correlations occurred between $\mathrm{MD}$ and pain intensity in the ipsilateral Vp $(r=0.626, p=0.01)$ and between MD and pain duration in the ipsilateral nerve entry region $(r=0.521, p=0.038)$ and the ipsilateral TL $(p=0.513, p=0.042)$. No other significant correlations were observed. Comparison of these clusters found no significant difference in MD values between those PTN subjects who used analgesic medication and those who did not. Furthermore, comparison of those subjects whose images were collected in the evening with those collected in the morning also resulted in significant difference in any cluster.

In addition to changes in MD, DTI analysis also revealed significant FA differences in a number of brainstem sites (Fig. 3, Table 2). Compared with controls, PTN subjects displayed significantly increased FA in the region of the ipsilateral SpV; in the region of the subnucleus interpolaris and oralis (mean \pm SEM FA: controls $0.18 \pm 0.008$, PTN $0.25 \pm 0.017$ ), bilaterally in the region of the trigeminal nerve tract within the pons (ipsilateral: controls $0.32 \pm 0.009$, PTN $0.41 \pm 0.007$; contralateral: controls $0.45 \pm 0.012$, PTN $0.51 \pm 0.014)$, and in the ipsilateral TL in the midbrain (controls $0.31 \pm 0.007$, PTN $0.40 \pm 0.015$ ). No decreases in FA were observed. In these significant clusters, in PTN subjects, significant correlations occurred between FA in the ipsilateral nerve entry region and pain intensity $(r=-0.579, p=0.019)$ and duration $(r=-0.513, p=0.042)$. No other significant correlations were observed. Furthermore, comparison of these clusters found no significant difference in MD values between those PTN subjects who used analgesic medication and those who did not and in those subjects whose images were collected in the morning compared with those collected in the evening.

\section{DTI and VBM overlap}

Brainstem regions that displayed both gray matter volume and diffusion changes were also determined. In a discrete region of the ipsilateral SpV oralis (MNI coordinates: $x=-8, y=-40$, $y=-47$, cluster size $=13 \mathrm{~mm}^{3}$ ), gray matter volume decreased, MD decreased, and FA increased (Fig. 4). Although no difference in gray matter volume was observed in the SpV interpolaris, discrete clusters of MD decrease and FA increase were observed, although not overlapping. Furthermore, within the SpV caudalis (MNI coordinates: $x=-4, y=-46, y=-64$ ), no significant differences between controls and PTN subjects were observed in gray matter volume (controls $0.20 \pm 0.01$ PTN $0.21 \pm 0.02 ; p=$ 0.91 ), MD (controls 0.59 \pm 0.05 ; PTN $0.71 \pm 0.04 ; p=0.09$ ), or FA (controls $0.28 \pm 0.03$; PTN $0.31 \pm 0.01 ; p=0.36$ ). 


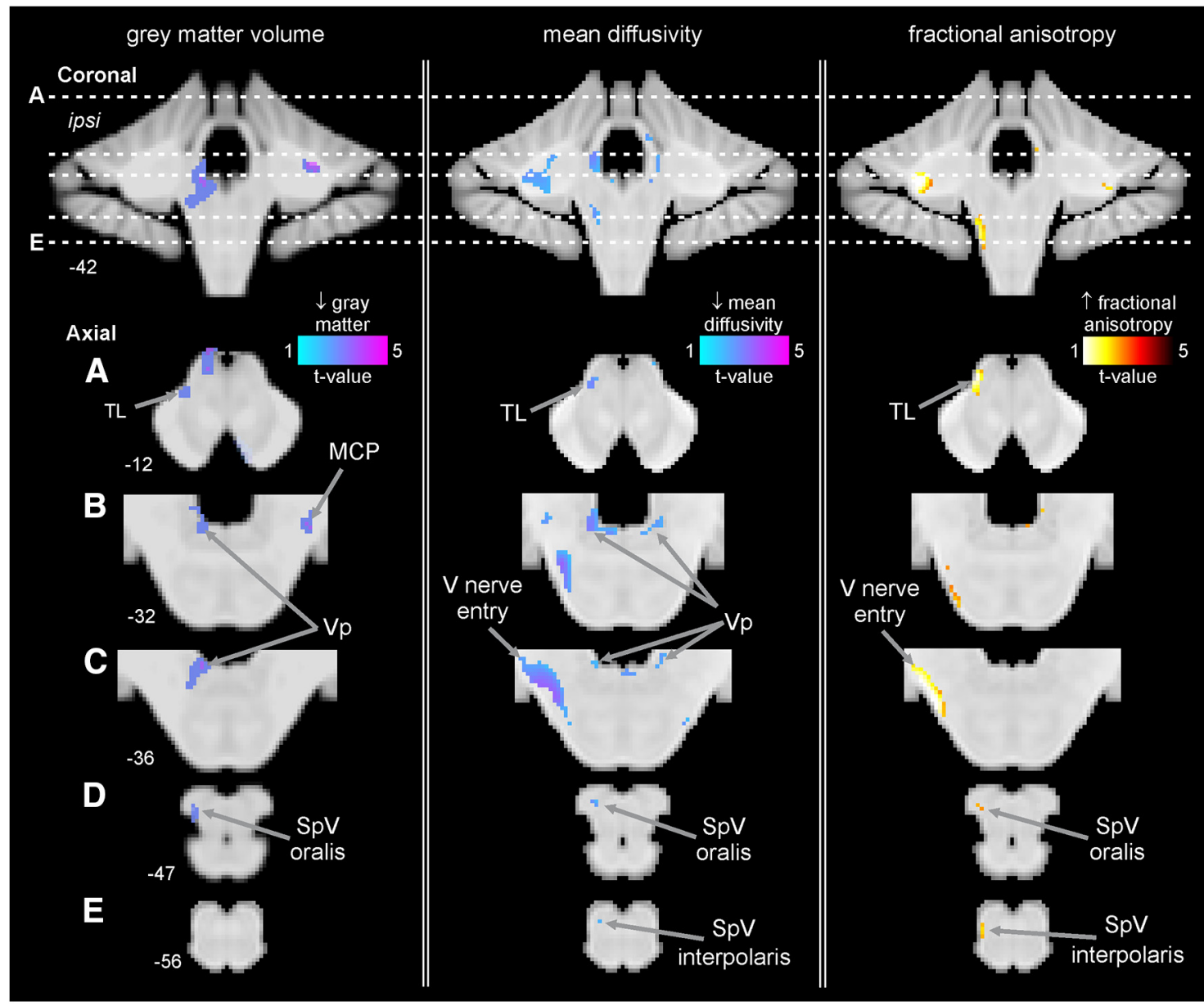

Figure 3. Regions of structural difference in subjects with PTN compared with pain-free control subjects overlaid onto template axial and coronal T1-weighted images. Slice locations in MNI space are indicated at the lower left of each image. Left, Regional gray matter volume decreases (cool color scale) in subjects with PTN compared with pain-free controls. Subjects with PTN have lower gray matter volumes in the ipsilateral (to highest ongoing pain) SpV oralis, ipsilateral Vp, contralateral MCP, and the ipsilateral TL. Middle, Regional MD decreases (cool color scale) in subjects with PTN compared with pain-free controls. Subjects with PTN have lower MD in the ipsilateral SpV oralis and interpolaris, ipsilateral V nerve entry, bilateral Vp, and ipsilateral TL. Right, Regional FA increases (hot color scale) in subjects with PTN compared with pain-free controls. Subjects with PTN have higher FA in the ipsilateral SpV oralis and interpolaris, ipsilateral V nerve entry, and the ipsilateral TL.

Table 2. MNI coordinates of significant grey matter volume and diffusion value differences between PTN and control subjects

\begin{tabular}{|c|c|c|c|c|c|}
\hline & \multicolumn{3}{|c|}{ MNI coordinates } & \multirow[b]{2}{*}{ Cluster size } & \multirow[b]{2}{*}{ Z-score } \\
\hline & $x$ & $y$ & $z$ & & \\
\hline \multicolumn{6}{|l|}{ Grey matter volume: PTN < controls } \\
\hline Ipsilateral SpV oralis & -9 & -38 & -45 & 10 & 3.80 \\
\hline Ipsilateral Vp & -7 & -44 & -32 & 164 & 3.67 \\
\hline Contralateral middle cerebellar peduncle & 24 & -43 & -32 & 76 & 4.82 \\
\hline Ipsilateral trigeminal lemniscus & -9 & -29 & -20 & 38 & 3.73 \\
\hline \multicolumn{6}{|l|}{ Mean diffusivity: PTN < controls } \\
\hline Ipsilateral SpV interpolaris & -7 & -43 & -55 & 6 & 3.42 \\
\hline Ipsilateral SpV oralis & -8 & -41 & -49 & 14 & 3.52 \\
\hline Ipsilateral V nerve entry & -2 & -36 & -36 & 232 & 5.20 \\
\hline \multicolumn{6}{|l|}{ Vp } \\
\hline Ipsilateral & -9 & -39 & -31 & 67 & 5.40 \\
\hline Contralateral & 9 & -43 & -39 & 56 & 4.42 \\
\hline Ipsilateral trigeminal lemniscus & -10 & -30 & -23 & 88 & 5.66 \\
\hline \multicolumn{6}{|l|}{ Fractional anisotropy: PTN $>$ controls } \\
\hline Ipsilateral SpV & -9 & -42 & -54 & 56 & 3.87 \\
\hline Ipsilateral V nerve entry & -24 & -38 & -39 & 215 & 5.51 \\
\hline Ipsilateral trigeminal lemniscus & -10 & -30 & -30 & 73 & 5.00 \\
\hline
\end{tabular}

V, Trigeminal.

\section{Tractography}

Tractography identified the REZ of the trigeminal nerve in all PTN and control subjects, the spinal trigeminal tract in 33\% of
PTN and $63 \%$ of control subjects, the ascending trigeminothalamic tract in all PTN and control subjects, and the crossing trigeminothalamic tract in all PTN and $94 \%$ of control subjects. Group analysis of the average FA and MD values in each ipsilateral and contralateral (to highest pain) tract revealed no difference in PTN subjects compared with controls in the REZ of the trigeminal nerve, the spinal trigeminal tract, the ipsilateral ventral trigeminothalmic tract, or the contralateral ventral trigeminothalamic tract. FA and MD group means for each tract are given in Table 3.

\section{Discussion}

The results of this study reveal that chronic neuropathic pain is associated with anatomical changes in the region of the primary synapse. More specifically, PTN subjects displayed decreased gray matter volume, decreased $\mathrm{MD}$, and increased FA in the region of the $\mathrm{SpV}$. Strikingly, PTN subjects did not display any significant differences in the anatomy of the trigeminal nerve, the spinal trigeminal tract, nor the ventral trigeminothalamic tracts. These data suggest that chronic neuropathic pain is associated with anatomical changes at the level of the primary synapse- the SpV — whereas the anatomy of $\mathrm{SpV}$ afferents and efferents remains unaffected.

Because it is the generally held view that nociceptive input from the orofacial region is initially processed in $\mathrm{SpV}$ caudalis, 


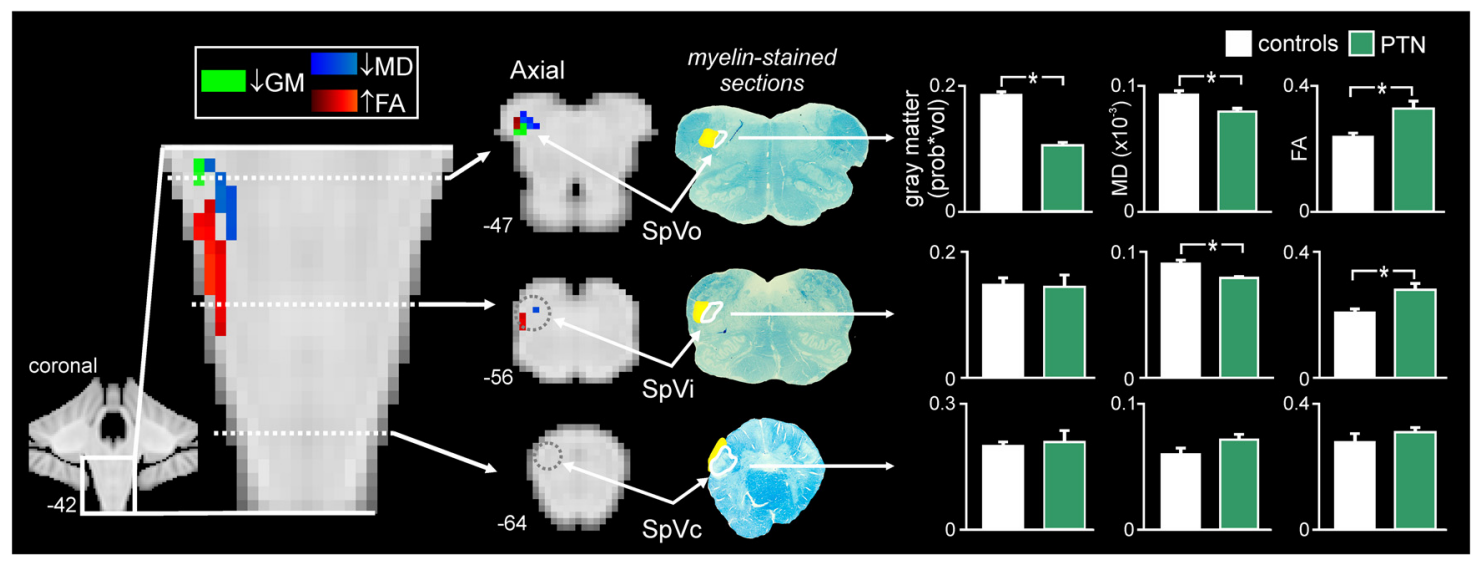

Figure 4. Gray matter (GM) volume decreases (light green), MD decreases (dark blue), and FA increases (red) in the SpV oralis and interpolaris in subjects with PTN compared with pain-free controls. Clusters are overlaid onto coronal and axial brainstem template images. Slice locations in MNI space are indicated at the lower left of each image. Corresponding myelin-stained axial sections indicating SpV subnuclei are shown to the right. The nuclei are outlined in white and the tract shaded yellow. Bar graphs of mean ( \pm SEM) GM volumes (probability*volume), mean MD $\left(\times 10^{-3} \mu \mathrm{m} / \mathrm{msec}\right.$ ) values, and mean FA values calculated from the clusters of significant difference in the SpV oralis and interpolaris and a manually defined ROI within the caudalis (MNI coordinates: $x=-4, y=-46, y=-64$ ) are shown to the far right of the figure. ${ }^{*}$ Significant difference determined in the voxel-by-voxel analysis.

Table 3. Average ( \pm SEM) FA and MD $\left(\times 10^{-3} \mu \mathrm{m} / \mathrm{msec}\right)$ values for the ipsilateral and contralateral (to pain) tracts for PTN and control subjects

\begin{tabular}{|c|c|c|c|c|}
\hline & Controls & PTN & & $p$-valu \\
\hline \multicolumn{5}{|c|}{$\begin{array}{l}\text { Trigeminal nerve (root entry } \\
\text { zone) }\end{array}$} \\
\hline \multirow[t]{2}{*}{ FA } & $0.3 \pm 0.024$ & Ipsilateral & $0.31 \pm 0.027$ & 0.64 \\
\hline & & Contralateral & $0.34 \pm 0.039$ & 0.84 \\
\hline \multirow[t]{2}{*}{ MD } & $1.97 \pm 0.144$ & Ipsilateral & $2.01 \pm 0.166$ & 0.88 \\
\hline & & Contralateral & $1.94 \pm 0.174$ & 0.89 \\
\hline \multicolumn{5}{|c|}{ Spinal trigeminal tract } \\
\hline \multirow[t]{2}{*}{ FA } & $0.52 \pm 0.031$ & Ipsilateral & $0.46 \pm 0.015$ & 0.24 \\
\hline & & Contralateral & $0.53 \pm 0.077$ & 0.97 \\
\hline \multirow[t]{2}{*}{ MD } & $0.87 \pm 0.065$ & Ipsilateral & $0.82 \pm 0.103$ & 0.66 \\
\hline & & Contralateral & $0.85 \pm 0.18$ & 0.88 \\
\hline \multicolumn{5}{|c|}{$\begin{array}{l}\text { Ipsilateral trigeminothalamic } \\
\text { tract }\end{array}$} \\
\hline \multirow[t]{2}{*}{ FA } & $0.57 \pm 0.028$ & Ipsilateral & $0.60 \pm 0.042$ & 0.57 \\
\hline & & Contralateral & $0.57 \pm 0.028$ & 0.06 \\
\hline \multirow[t]{2}{*}{ MD } & $0.70 \pm 0.049$ & Ipsilateral & $0.64 \pm 0.062$ & 0.42 \\
\hline & & Contralateral & $0.63 \pm 0.063$ & 0.34 \\
\hline \multicolumn{5}{|c|}{$\begin{array}{l}\text { Contralateral trigeminothalamic } \\
\text { tract }\end{array}$} \\
\hline \multirow[t]{2}{*}{ FA } & $0.57 \pm 0.029$ & Ipsilateral & $0.58 \pm 0.032$ & 0.77 \\
\hline & & Contralateral & $0.62 \pm 0.056$ & 0.42 \\
\hline \multirow[t]{2}{*}{ MD } & $0.69 \pm 0.048$ & Ipsilateral & $0.66 \pm 0.051$ & 0.69 \\
\hline & & Contralateral & $0.60 \pm 0.076$ & 0.28 \\
\hline
\end{tabular}

$p$-values are reported for two-sample $t$ test between PTN and controls.

one might initially conclude from our data that PTN is not associated with changes in the region of the primary synapse. However, behavioral, anatomical, and electrophysiological evidence from experimental animal investigations suggest that more rostral nuclei, including SpV oralis, $\mathrm{SpV}$ interpolaris, and Vp, have a primary role in processing noxious input from oral and perioral regions (Sessle and Greenwood, 1976; Marfurt and Turner, 1984; Sessle, 2000). In the majority of PTN subjects in this investigation, the presumptive initiating event was a dental procedure and the distribution of their ongoing pain was centered in oral and perioral regions. This characteristic likely accounts for our findings of a volumetric loss specifically within the SpV oralis and Vp without anatomical changes in SpV caudalis.

The nature of the cellular changes underlying the detected MRI changes is unclear. Although a decrease in gray matter vol- ume may result from neuronal loss, it may also result from shrinkage or atrophy of neurons or glia or synaptic loss (May and Gaser, 2006). In addition, MD and FA are markers of more subtle changes in tissue microstructure that may result from tissue shrinkage and dense packing of myelinated fibers as a result of neurodegeneration and gliosis (Sierra et al., 2011). Consistent with our findings, animal models of neuropathic pain show nerve injury evokes neuronal degeneration in the region of recipient primary synapse (Sugimoto et al., 1990; Azkue et al., 1998; Whiteside and Munglani, 2001; de Novellis et al., 2004; Scholz et al., 2005). This neuronal degeneration is thought to result from excessive, ongoing afferent excitation (Sloviter and Damiano, 1981; Coggeshall et al., 1993), a theory supported by reports that myelinated primary afferents in nerve-injured animals discharge ectopically at high frequencies, thus providing aberrant excitatory input (Khan et al., 2002; Chaplan et al., 2003; Amir et al., 2005) that in turn is responsible for the protracted induction of neuronal loss (Coggeshall et al., 1993; Scholz et al., 2005). Furthermore, the number of neurons in superficial laminae is reduced by $\sim 22 \%$ at 4 weeks after injury, including a $~ 25 \%$ loss of GABAergic inhibitory interneurons (Scholz et al., 2005). This inhibitory neuron loss is likely responsible for the observed decrease in dorsal horn postsynaptic inhibition (Moore et al., 2002). Dorsal horn neuronal degeneration appears to play an important role in the establishment of chronic pain because a reduction of this neuronal loss by administration of caspase apoptosis inhibitors reduces the occurrence of neuropathic pain-like behaviors in experimental animals (Whiteside and Munglani, 2001; Scholz et al., 2005).

In direct contrast to the anatomical changes at the primary synapse, the afferent and efferent projections appear unaffected. At first glance, this lack of change is surprising given that the etiology of PTN is often attributed to direct trauma of the trigeminal nerve or any of its tributaries (Benoliel et al., 2012). Although we did not find significant diffusion differences along the spinal trigeminal tract, we did find localized diffusion changes in the pons in the region where the trigeminal nerve enters. Furthermore, the degree of change was significantly correlated to ongoing pain intensity and duration. Given that, at this entry point, large diameter fibers are tracking toward $\mathrm{Vp}$ and small diameter fibers to the spinal trigeminal tract, it is possible that the diffusion change results from this fiber separation. Indeed, we also found significant diffusion changes in $\mathrm{Vp}$, which may suggest that these 
changes are related to altered large diameter fibers synapsing in $\mathrm{Vp}$. It is possible that these changes are associated with the altered central processing of innocuous somatosensory stimuli that occurs in PTN subjects (Gustin et al., 2012).

With regard to the peripheral nerve, in animal models of neuropathic pain, neuromas form at the site of nerve injury and both myelinated and unmyelinated axons show a marked decrease distal to the site of injury, but the nerve proximal to the injury is spared this neuronal loss (Carlton et al., 1991; Stanisz et al., 2001). Furthermore, after an extended period, the distal degeneration of the nerve undergoes significant regeneration such that it appears essentially normal (Gautron et al., 1990; Coggeshall et al., 1993; Stanisz et al., 2001; Taylor and Ribeiro-da-Silva, 2011). These findings are consistent with our data in that we found no diffusion differences in the REZ of the trigeminal nerve or in the spinal trigeminal tract in PTN subjects, suggesting that, in the long term, the proximal microstructure of the trigeminal nerve is not altered (Stanisz et al., 2001). This is supported by our previous investigation in which we found volumetric and crosssectional area increases in the REZ of the trigeminal nerve in PTN subjects (Wilcox et al., 2013), perhaps as a result of this regeneration (Watson et al., 2007).

We also found no difference in the diffusion properties of the ipsilateral or contralateral ventral trigeminothalamic tract in PTN subjects, suggesting that the integrity of this tract is not substantially altered. We did, however, find discrete diffusion and volume changes in the midbrain region encompassing the trigeminal lemniscus, the degree of which was significantly correlated to ongoing pain intensity. Given the lack of change in fibers ascending from $\mathrm{SpV}$, this change may reflect altered large diameter afferent changes from fibers ascending from $\mathrm{Vp}$, although the degree of change was correlated with ongoing pain, suggesting a small diameter effect. The trigeminothalamic tract conveys noxious orofacial information from the $\mathrm{SpV}$ to the cerebral cortex largely via the somatosensory thalamus (Craig, 2004). Although, in animal models, loss of primary afferent neurons (substance $\mathrm{P}$ immunoreactive fibers) and GABAergic interneurons in the dorsal horn have been shown (de Novellis et al., 2004; Scholz et al., 2005), the fate of ascending projection neurons originating in the dorsal horn has not been specifically investigated. Despite a reported loss of $\sim 22 \%$ of dorsal horn neurons, our data suggest that these are not thalamic projecting neurons. One consideration may be the relative number of ventral trigeminothalamic tract fibers originating from each $\mathrm{SpV}$ subnucleus because the vast majority originate in $\mathrm{SpV}$ caudalis and the caudalis/interpolaris transition zone, whereas $\mathrm{SpV}$ interpolaris and oralis projections are relatively sparse (Matsushita et al., 1982; Shigenaga et al., 1986). Therefore, any degeneration of these fibers may be too subtle to detect using DTI methods.

Our observations of discrete anatomical changes in the region of the primary synapse, in combination with an absence of diffusion changes within the trigeminothalamic tract, complement our previous findings of a specific, regional gray matter loss within the somatosensory thalamus of PTN subjects (Gustin et al., 2011). Indeed, it appears that a volumetric loss within the somatosensory thalamus may be a unifying observation in chronic neuropathic pain (Apkarian et al., 2004; Gustin et al., 2010). These findings, taken together, are consistent with the idea that the neuronal changes associated with neuropathic pain are tract specific and may result from excitotoxic, trans-synaptic neuronal effects along ascending pain pathways. Although evidence of specific trans-synaptic effects is not established, some experimental animal investigations report neuronal loss in pain pathway recipient regions such as the midbrain periaqueductal gray matter (Mor et al., 2011) and the rostral ventromedial medulla (Leong et al., 2011). Interestingly, in a previous investigation, we found no evidence of altered resting blood flow in SpV or the somatosensory thalamus in PTN subjects, although blood flow was reduced in the thalamic reticular nucleus (Henderson et al., 2013; Youssef et al., 2014). One interpretation of these results is that neuropathic pain is does not involve overt activation of pain pathways, but instead results from changes in the pattern of neural firing. Indeed, human and experimental animal studies suggest that thalamocortical dysrhythmia may give rise to the spontaneous perception of pain in neuropathic conditions (Wang and Thompson, 2008; Walton and Llinas, 2010).

Overall, our findings suggest that chronic neuropathic pain in humans is associated with anatomical changes in the regions of the primary synapse. This observation, together with our previous results in this pain group, serves as evidence of central anatomical changes at multiple levels of the pain pathway, which may underlie the abnormal neuronal function associated with the positive sensory symptoms (allodynia, hyperalgesia, and spontaneous pain) which occur in chronic neuropathic pain conditions. Determining the relative importance of these brain changes in the expression of these positive sensory symptoms may lead to more targeted treatments for chronic neuropathic pain.

\section{References}

Amir R, Kocsis JD, Devor M (2005) Multiple interacting sites of ectopic spike electrogenesis in primary sensory neurons. J Neurosci 25:25762585. CrossRef Medline

Apkarian AV, Sosa Y, Sonty S, Levy RM, Harden RN, Parrish TB, Gitelman DR (2004) Chronic back pain is associated with decreased prefrontal and thalamic gray matter density. J Neurosci 24:10410-10415. CrossRef Medline

Azkue JJ, Zimmermann M, Hsieh TF, Herdegen T (1998) Peripheral nerve insult induces NMDA receptor-mediated, delayed degeneration in spinal neurons. Eur J Neurosci 10:2204-2206. CrossRef Medline

Benoliel R, Zadik Y, Eliav E, Sharav Y (2012) Peripheral painful traumatic trigeminal neuropathy: clinical features in 91 cases and proposal of novel diagnostic criteria. J Orofac Pain 26:49-58. Medline

Carlton SM, Dougherty PM, Pover CM, Coggeshall RE (1991) Neuroma formation and numbers of axons in a rat model of experimental peripheral neuropathy. Neurosci Lett 131:88-92. CrossRef Medline

Chaplan SR, Guo HQ, Lee DH, Luo L, Liu C, Kuei C, Velumian AA, Butler MP, Brown SM, Dubin AE (2003) Neuronal hyperpolarizationactivated pacemaker channels drive neuropathic pain. J Neurosci 23: 1169-1178. Medline

Coggeshall RE, Dougherty PM, Pover CM, Carlton SM (1993) Is large myelinated fiber loss associated with hyperalgesia in a model of experimental peripheral neuropathy in the rat? Pain 52:233-242. CrossRef Medline

Costigan M, Scholz J, Woolf CJ (2009) Neuropathic pain: a maladaptive response of the nervous system to damage. Annu Rev Neurosci 32:1-32. CrossRef Medline

Craig AD (2004) Distribution of trigeminothalamic and spinothalamic lamina I terminations in the macaque monkey. J Comp Neurol 477:119148. CrossRef Medline

de Novellis V, Siniscalco D, Galderisi U, Fuccio C, Nolano M, Santoro L, Cascino A, Roth KA, Rossi F, Maione S (2004) Blockade of glutamate mGlu5 receptors in a rat model of neuropathic pain prevents early overexpression of pro-apoptotic genes and morphological changes in dorsal horn lamina II. Neuropharmacology 46:468-479. CrossRef Medline

Diedrichsen J (2006) A spatially unbiased atlas template of the human cerebellum. Neuroimage 33:127-138. CrossRef Medline

Dougherty RF, Ben-Shachar M, Bammer R, Brewer AA, Wandell BA (2005) Functional organization of human occipital-callosal fiber tracts. Proc Natl Acad Sci U S A 102:7350-7355. CrossRef Medline

Friston KJ, Holmes AP, Worsley KJ, Poline JP, Frith CD, Frackowiak RSJ (1994) Statistical parametric maps in functional imaging: a general linear approach. Hum Brain Mapp 2:189-210. CrossRef

Gautron M, Jazat F, Ratinahirana H, Hauw JJ, Guilbaud G (1990) Altera- 
tions in myelinated fibres in the sciatic nerve of rats after constriction: possible relationships between the presence of abnormal small myelinated fibres and pain-related behaviour. Neurosci Lett 111:28-33. CrossRef Medline

Gustin SM, Wrigley PJ, Siddall PJ, Henderson LA (2010) Brain anatomy changes associated with persistent neuropathic pain following spinal cord injury. Cereb Cortex 20:1409-1419. CrossRef Medline

Gustin SM, Peck CC, Wilcox SL, Nash PG, Murray GM, Henderson LA (2011) Different pain, different brain: thalamic anatomy in neuropathic and non-neuropathic chronic pain syndromes. J Neurosci 31:5956-5964. CrossRef Medline

Gustin SM, Peck CC, Cheney LB, Macey PM, Murray GM, Henderson LA (2012) Pain and plasticity: is chronic pain always associated with somatosensory cortex activity and reorganization? J Neurosci 32:14874-14884. CrossRef Medline

Henderson LA, Peck CC, Petersen ET, Rae CD, Youssef AM, Reeves JM, Wilcox SL, Akhter R, Murray GM, Gustin SM (2013) Chronic pain: lost inhibition? J Neurosci 33:7574-7582. CrossRef Medline

Iwata K, Imamura Y, Honda K, Shinoda M (2011) Physiological mechanisms of neuropathic pain: the orofacial region. Int Rev Neurobiol 97: 227-250. CrossRef Medline

Katz J, Seltzer Z (2009) Transition from acute to chronic postsurgical pain: risk factors and protective factors. Expert Rev Neurother 9:723-744. CrossRef Medline

Khan GM, Chen SR, Pan HL (2002) Role of primary afferent nerves in allodynia caused by diabetic neuropathy in rats. Neuroscience 114:291-299. CrossRef Medline

Lambert C, Chowdhury R, Fitzgerald TH, Fleming SM, Lutti A, Hutton C, Draganski B, Frackowiak R, Ashburner J (2013) Characterizing aging in the human brainstem using quantitative multimodal MRI analysis. Front Hum Neurosci 7:462. CrossRef Medline

Leong ML, Gu M, Speltz-Paiz R, Stahura EI, Mottey N, Steer CJ, Wessendorf M (2011) Neuronal loss in the rostral ventromedial medulla in a rat model of neuropathic pain. J Neurosci 31:17028-17039. CrossRef Medline

Marfurt CF, Turner DF (1984) The central projections of tooth pulp afferent neurons in the rat as determined by the transganglionic transport of horseradish peroxidase. J Comp Neurol 223:535-547. CrossRef Medline

Matsushita M, Ikeda M, Okado N (1982) The cells of origin of the trigeminothalamic, trigeminospinal and trigeminocerebellar projections in the cat. Neuroscience 7:1439-1454. CrossRef Medline

May A (2008) Chronic pain may change the structure of the brain. Pain 137:7-15. CrossRef Medline

May A, Gaser C (2006) Magnetic resonance-based morphometry: a window into structural plasticity of the brain. Curr Opin Neurol 19:407-411. CrossRef Medline

Melzack R (1975) The McGill Pain Questionnaire: major properties and scoring methods. Pain 1:277-299. CrossRef Medline

Melzack R, Loeser JD (1978) Phantom body pain in paraplegics: evidence for a central "pattern generating mechanism" for pain. Pain 4:195-210. Medline

Moore KA, Kohno T, Karchewski LA, Scholz J, Baba H, Woolf CJ (2002) Partial peripheral nerve injury promotes a selective loss of GABAergic inhibition in the superficial dorsal horn of the spinal cord. J Neurosci 22:6724-6731. Medline

Mor D, Bembrick AL, Austin PJ, Keay KA (2011) Evidence for cellular injury in the midbrain of rats following chronic constriction injury of the sciatic nerve. J Chem Neuroanat 41:158-169. CrossRef Medline

Naidich TP, Duvernoy HM, Delman BN, Sorensen AG, Kollias SS, M. HE (2009) Duvernoy's atlas of the human brain stem and cerebellum. Vienna: Springer/Wien.

Nurmikko TJ, Eldridge PR (2001) Trigeminal neuralgia-pathophysiology, diagnosis and current treatment. Br J Anaesth 87:117-132. CrossRef Medline

Paxinos G, Huang X (1995) Atlas of the human brainstem, Ed 1. San Diego: Academic.
Scholz J, Broom DC, Youn DH, Mills CD, Kohno T, Suter MR, Moore KA, Decosterd I, Coggeshall RE, Woolf CJ (2005) Blocking caspase activity prevents transsynaptic neuronal apoptosis and the loss of inhibition in lamina II of the dorsal horn after peripheral nerve injury. J Neurosci 25:7317-7323. CrossRef Medline

Sessle BJ (2000) Acute and chronic craniofacial pain: brainstem mechanisms of nociceptive transmission and neuroplasticity, and their clinical correlates. Crit Rev Oral Biol Med 11:57-91. CrossRef Medline

Sessle BJ, Greenwood LF (1976) Inputs to trigeminal brain stem neurones from facial, oral, tooth pulp and pharyngolaryngeal tissues: I. Responses to innocuous and noxious stimuli. Brain Res 117:211-226. CrossRef Medline

Shigenaga Y, Suemune S, Nishimura M, Nishimori T, Sato H, Ishidori H, Yoshida A, Tsuru K, Tsuiki Y, Dateoka Y, et al. (1986) Topographic representation of lower and upper teeth within the trigeminal sensory nuclei of adult cat as demonstrated by the transganglionic transport of horseradish peroxidase. J Comp Neurol 251:299-316. CrossRef Medline

Sierra A, Laitinen T, Lehtimäki K, Rieppo L, Pitkänen A, Gröhn O (2011) Diffusion tensor MRI with tract-based spatial statistics and histology reveals undiscovered lesioned areas in kainate model of epilepsy in rat. Brain Struct Funct 216:123-135. CrossRef Medline

Sloviter RS, Damiano BP (1981) Sustained electrical stimulation of the perforant path duplicates kainate-induced electrophysiological effects and hippocampal damage in rats. Neurosci Lett 24:279-284. CrossRef Medline

Stanisz GJ, Midha R, Munro CA, Henkelman RM (2001) MR properties of rat sciatic nerve following trauma. Magn Reson Med 45:415-420. CrossRef Medline

Sugimoto T, Bennett GJ, Kajander KC (1990) Transsynaptic degeneration in the superficial dorsal horn after sciatic nerve injury: effects of a chronic constriction injury, transection, and strychnine. Pain 42:205-213. CrossRef Medline

Taylor AM, Ribeiro-da-Silva A (2011) GDNF levels in the lower lip skin in a rat model of trigeminal neuropathic pain: implications for nonpeptidergic fiber reinnervation and parasympathetic sprouting. Pain 152:15021510. CrossRef Medline

Tracey I, Bushnell MC (2009) How neuroimaging studies have challenged us to rethink: is chronic pain a disease? J Pain 10:1113-1120. CrossRef Medline

Valsasina P, Horsfield MA, Rocca MA, Absinta M, Comi G, Filippi M (2012) Spatial normalization and regional assessment of cord atrophy: voxelbased analysis of cervical cord 3D T1-weighted images. AJNR Am J Neuroradiol 33:2195-2200. CrossRef Medline

Walton KD, Llinas RR (2010) Central pain as a thalamocortical dysrhythmia: a thalamic efference disconnection? In: Kruger L, Light AR (editors). Translational pain research: from mouse to man. Boca Raton, FL: CRC.

Wang G, Thompson SM (2008) Maladaptive homeostatic plasticity in a rodent model of central pain syndrome: thalamic hyperexcitability after spinothalamic tract lesions. J Neurosci 28:11959-11969. CrossRef Medline

Watson CP, Stinson JN, Dostrovsky JO, Hawkins C, Rutka J, Forrest C (2007) Nerve resection and re-location may relieve causalgia: a case report. Pain 132:211-217. CrossRef Medline

Whiteside GT, Munglani R (2001) Cell death in the superficial dorsal horn in a model of neuropathic pain. J Neurosci Res 64:168-173. CrossRef Medline

Wilcox SL, Gustin SM, Eykman EN, Fowler G, Peck CC, Murray GM, Henderson LA (2013) Trigeminal nerve anatomy in neuropathic and nonneuropathic orofacial pain patients. J Pain 14:865-872. CrossRef Medline

Woolf CJ (1993) The pathophysiology of peripheral neuropathic pain-abnormal peripheral input and abnormal central processing. Acta Neurochir Suppl (Wien) 58:125-130. Medline

Youssef AM, Gustin SM, Nash PG, Reeves JM, Petersen ET, Peck CC, Murray GM, Henderson LA (2014) Differential brain activity in subjects with painful trigeminal neuropathy and painful temporomandibular disorder. Pain 155:467-475. Medline 